\title{
DECODIFICANDO AS REPORTAGENS BIRMANESAS SOBRE A CHINA EM 2012
}

ZHou LeI

Resumo: Em anos recentes, os interesses acadêmicos chineses se direcionaram da China central para uma região marginalizada no sudeste, influenciados por mudanças econômicas, políticas e étnicas. De modo a compreender a transformação nesta região, é preciso mergulhar nos ricos e complexos contextos socioculturais, etnopolíticos e antropológicos. Com base na análise de conteúdo e nos dados etnográficos em casos ambientais, este artigo analisa como a reportagem da mídia internacional em Mianmar/ Birmânia mudou, e com quais características, especialmente nos assuntos relativos à China.

Palavras-chave: Mídia birmanesa; Antropologia da mídia; Movimento ambiental; Contexto de reforma; Políticas internas.

\section{DECODING BURMESE REPORTAGE OF CHINA IN 2012}

\section{$\overline{\text { ZHOU LEI }}$}

Pós-doutorado no Instituto de Antropologia Social da Universidade de Nanjing; pesquisador (2008-2009), no Departamento de Antropologia da London School of Economics and Political Science. Fundador do Oriental Danology Institute e do BRICS FUTURES.
Abstract: In recent years, Chinese academic interests have shifted from central China to a marginalized region in Southwest, influenced by the economic, political and ethnic changes. In order to understand the transformation in this region, it is necessary to delve into the rich and complex socio-cultural, ethno-political, and anthropological contexts. On the basis of content analysis and ethnographic data on environmental cases, this paper analyzes how international media and international reporting in Myanmar has changed and with what characteristics, especially on Chineserelated issues.

Keywords: Burmese media; Media anthropology; Environmental movement; Reform context; Infra-politics. 


\section{INTRODUÇÃO}

Este artigo busca examinar as ricas conotações refletidas pela mídia ao lidar com políticas ambientais e justiça social em um contexto globalizado. Desde 2010, o autor iniciou um novo esforço etnográfico, com o apoio do Oriental Danology Institute (ODI), intitulado "Enxergar a China Invisível e o Mundo: Conflitos e Desafios". Esta pesquisa tenta analisar mercados emergentes como a Birmânia, o Brasil, a Índia, a África do Sul e o Nepal, para estudar o meio-ambiente e o impacto social dos investimentos chineses no exterior.

Embora seja sua vizinha, muito poucos chineses estão realmente familiarizados com a Birmânia como país e conjunto cultural, e isto se aplica, de um modo geral, tanto à academia quanto ao povo chinês. Por exemplo, raramente, senão nunca, os chineses estão cientes de que "China", como substantivo, pronunciado "/ deh yout/", no idioma birmanês, lembra uma palavra similar que significa "malandro ou desonesto". A interação socioeconômica entre a China e a Birmânia pode ser traçada a milhares de anos, quando o povo chinês acreditava que parte da Birmânia pertencia à China como um protetorado. Ao contrário da "engenhosidade" demonstrada pela palavra birmanesa mencionada anteriormente, os chineses tendem a acreditar que eles são mais favoráveis a comerciantes estrangeiros e não negociam menores lucros (houwang bolai significa rendimentos favoráveis ou "rendimentos grossos" e incalculáveis em termos de benefício ou "pequeno autobenefício"), assim, a palavra "deh yout" é tratada pelos chineses como contrafactual e contra-intuitiva.

Outra palavra usada com frequência pelo governo chinês nas relações com a Birmânia é "baobo", que significa "irmãos" e "relações fraternais", contudo, no contexto birmanês, "baobo" assume a conotação de "falso" e "simpatia" politicamente orquestrada (como nas notícias propagandísticas governamentais).

Uma análise aprofundada das reportagens birmanesas que tratam de assuntos chineses, neste contexto, tende a evocar mais pistas para desmascarar o rígido sistema retórico atual da China autoritária versus o regime birmanês pós-Junta. 
Por conta das limitações do artigo, não examinaremos a pertinência entre o caso birmanês e o caso brasileiro; contudo, todas as questões étnicas, protestos e campanha de direitos humanos, manifestações de justiça social, estereótipo cultural, contestação política, desigualdades econômicas, disparidade de conhecimentos, como mencionados no caso em questão, podem ser encontrados em outros países do BRICS e no contexto de mercados emergentes.

Empresários e capitalistas globalizados estão bem melhores organizados e conduzidos do que pesquisadores em todos os destinos de seus investimentos, incluindo os BRICS e outros mercados emergentes. De modo a contrabalançar os efeitos negativos do capitalismo globalizado e dos conglomerados empresariais, a academia deveria ser mais atenta à interligação de diferentes casos baseados em análises aprofundadas.

\section{O CONTEXTO DA REFORMA PÓS-LIBERDADE DE IMPRENSA: DIAGNÓSTICO E PROGNÓSTICO}

As notícias selecionadas para análise de conteúdo foram retiradas de influentes meios de comunicação da sociedade birmanesa, consistindo de cinco grandes veículos midiáticos, e coletadas principalmente de abril a julho de 2012. Além da rotina de digitalizar o conteúdo noticioso, este artigo utiliza o episódio do protesto contra a passagem do oleoduto, de modo a esboçar a lógica e a textura da esfera midiática birmanesa. O foco da análise está nas primeiras-páginas, através de palavras e reportagens correlacionadas, com agitações e incidentes políticos, especialmente o milagroso ressurgimento de Aung San Suu Kyi, em 2013, depois de décadas de prisão domiciliar.

Em geral, o contexto da reforma da conturbada mudança política birmanesa teve um grande impacto nas reportagens e sua interação com as esferas da opinião pública doméstica e estrangeira, todas as mudanças, pequenas ou significativas, foram transformadas em notícias e em assuntos candentes para a inteligência internacional, incluindo a China. A era pós-liberdade de imprensa da mídia birmanesa deu origem a um ambiente dinâmico, senão consistente, e a uma nova agenda política, interligados com efervescentes conflitos étnicos e confrontos religiosos antagônicos. 
Para os leitores chineses e potenciais investidores, a confusa reestruturação da mídia acabou levando a uma "selva midiática" complicada e inadmissível, cheia de armadilhas e terrenos minados.

\section{ANÁLISE DE CONTEÚdO DO “MYANMAR AHLIN"}

Na Birmânia, dentre os quatro jornais diários nacionais, que consistem no Myanmar Ahlin, no Kyayon, no New Light of Myanmar e no Myawade, o Myanmar Ahlin é o mais influente. Fundado em 1914, quando a Birmânia ainda vivia seus dias coloniais, este jornal conseguiu se tornar o mais antigo e tradicional em assuntos que dizem respeito à reforma política e pró-independência. Por causa de sua influência, os outros três jornais compartilham muitas similaridades e tornam-se repetitivos em relação ao conteúdo e à uniformidade das opiniões do Myanmar Ahlin. Assim, este jornal pode ser percebido como um exemplo representativo da posição do governo birmanês e apresenta a opinião política oficial em importantes questões sociais. Neste sentido, este jornal é comparável à sua contraparte chinesa, o People's Daily (Renmin Ribao).

Em termos de conteúdo, estes jornais cobrem os seguintes assuntos: questões legais, Congresso, recursos humanos, agricultura, hidráulica, budismo, questões de etnia e paz, eleição, educação, proteção ambiental, construção urbana, desenvolvimento e reforma, Comissão Industrial e de Comércio da Birmânia, turismo, saúde, mídia e energia.

Baseado na análise de conteúdo, o principal objetivo político do Myanmar Ahlin são as questões étnicas, relacionadas a reconciliação étnica, desenvolvimento rural, construção urbana e questões de barragens. Dentre os quatro objetivos de desenvolvimento, o desenvolvimento rural é a base da revitalização econômica birmanesa com vistas à industrialização do país. Na posição de segundo maior exportador de feijão e maior produtor de arroz, o governo birmanês coloca bastante ênfase na atração de investimentos para a agricultura e na transferência de tecnologia agricultora, o que tem sido demonstrado em sua cobertura de mídia (a cobertura acerca de países estrangeiros se concentrou 
especificamente na ASEAN, ${ }^{1}$ Vietnã, Reino Unido, Estados Unidos, Japão, Nações Unidas, Alemanha, União Européia, Coréia, Índia, Cingapura, Tailândia, Laos e China).

Como Estado-membro da ASEAN, a Birmânia vê possibilidades de se inserir na área de livre-comércio China-ASEAN para gerar maiores lucros. Em 2015, a Birmânia será o Estado responsável pela presidência rotativa do ASEAN e o mundo estará presenciando uma primeira internacionalização deste Estado antes isolado. Dentre todos os países que interagem com a Birmânia, os visitantes mais freqüentes são a Tailândia, o Japão e a Índia. Quando o capital chinês experimentou um revés em vários de seus investimentos em represas, mineração e setores relacionados a recursos, estes três países tomaram a dianteira apresentando alternativas para o governo birmanês.

\section{COMMERCE WEEKLY}

Como uma revista semanal, o Commerce Weekly oferece notícias e análises, com a bênção do Departamento de Comércio da Birmânia. Minha análise se concentra em artigos de capa, consistindo de 80 deles, cobrindo 22 diferentes assuntos e 11 países. No topo das prioridades, Tailândia, Índia, ASEAN e China são os tópicos mais freqüentes; dentre outras questões econômicas regionais, esta revista aborda diversos tópicos geoeconômicos, tais como a Zona de Livre-Comércio China-ASEAN e a integração da ASEAN.

Em uma história de capa, "Como Dançar com o Dragão", esta revista analisa tendência futuras da interação econômica Birmânia-China. De acordo com a matéria, a China, como um dragão, fará um mergulho subterrâneo em busca de energia e recursos e, ao mesmo tempo, voar em direção ao mercado mundial. Como resultado disto, tanto a Ásia quanto a Europa estão repletos de produtos fabricados na China, como país-membro do CLMV ${ }^{2}$ a Birmânia competirá com a China, de maneira plena, na

\footnotetext{
1 Nota do Tradutor: ASEAN é a sigla em inglês que designa a Associação de Nações do Sudeste Asiático.

2 NT: CLMV é o grupo composto por Camboja, Laos, Birmânia/Myanmar e Vietnam.
} 
AFTA $^{3}$ em 2015. De modo a competir com a China, para o autor desta história, a Birmânia deveria emergir e reforçar suas proezas econômicas para espalhar produtos Made in Myanmar. Esta história representou bem a forma como o círculo de negócios e o público birmaneses enxergam a crescente influência da China e sua potencial ameaça à sociedade birmanesa.

\section{Fig.1 - Análise de conteúdo da cobertura econômica}

\begin{tabular}{|c|c|c|c|c|}
\hline \multirow{2}{*}{\begin{tabular}{|l|} 
Tópicos \\
Agricultura
\end{tabular}} & \multirow{2}{*}{$\begin{array}{l}\text { Categoria } \\
\text { Arroz }\end{array}$} & \multicolumn{2}{|c|}{ Freqüência } & \multirow[t]{2}{*}{ Total } \\
\hline & & 10 & \multirow[t]{8}{*}{32} & \\
\hline & Feijão & 13 & & \\
\hline & Milho & 1 & & \\
\hline & Manga & 1 & & \\
\hline & Borracha & 1 & & \\
\hline & Carvalho & 1 & & \\
\hline & Cana-de-açúcar & 2 & & \\
\hline & Outros & 3 & & \\
\hline \multicolumn{2}{|c|}{ Comércio e Negócios } & \multicolumn{2}{|l|}{11} & \\
\hline \multicolumn{2}{|l|}{ Automóveis } & \multicolumn{2}{|c|}{5} & \\
\hline \multicolumn{2}{|c|}{ Tarifas e Taxas } & \multicolumn{2}{|l|}{4} & \\
\hline \multirow[t]{2}{*}{ Finanças } & Dólar (EUA) & 4 & \multirow[t]{2}{*}{6} & \\
\hline & Ouro & 2 & & \\
\hline \multicolumn{2}{|c|}{ Administração e Reforma } & \multicolumn{2}{|l|}{7} & \\
\hline \multicolumn{3}{|l|}{ Pesca } & \multicolumn{2}{|l|}{3} \\
\hline \multicolumn{3}{|c|}{ Óleo de cozinha } & \multicolumn{2}{|l|}{2} \\
\hline \multicolumn{3}{|l|}{ Indústria } & \multicolumn{2}{|l|}{3} \\
\hline \multicolumn{3}{|c|}{ Área de Livre Comércio da ASEAN } & \multicolumn{2}{|l|}{3} \\
\hline \multicolumn{3}{|c|}{ AEC (Comunidade Econômica Asiática) } & \multicolumn{2}{|l|}{2} \\
\hline \multicolumn{3}{|l|}{ Outros } & \multicolumn{2}{|l|}{3} \\
\hline \multicolumn{3}{|l|}{ Energia } & \multicolumn{2}{|l|}{3} \\
\hline \multicolumn{3}{|c|}{ Roupas feitas sob medida } & \multicolumn{2}{|l|}{2} \\
\hline \multicolumn{3}{|l|}{22} & \multicolumn{2}{|l|}{86} \\
\hline
\end{tabular}

3 NT: AFTA é a sigla em inglês para Área de Livre Comércio da ASEAN (ASEAN Free Trade Area) 
A China e a Birmânia mantinham uma frequente, crônica, mas misteriosa interação durante o regime milita; no momento de democratização estão experimentando e reclassificando suas relações em diversos aspectos e de maneira profunda. A Birmânia está se juntando a uma nova ordem internacional que abre diversas oportunidades de desenvolvimento; responsabilizando-se por suas dramáticas e progressivas estratégias de reforma. Este "renascimento" vai criar diversas oportunidades para que os birmaneses definam uma era próspera de reforma. Até certo ponto, a Birmânia está pensando com sua própria lógica, tomando suas próprias iniciativas e evitando limitações políticas tradicionais, do mesmo jeito que a China fez na década de 1960, quando se libertou das chantagens soviéticas e do confinamento da Guerra Fria.

Embora a nova ordem sino-birmanesa ainda não esteja clara, o velho mecanismo e o estrato estão passando por uma transformação e virada teutônicas. Dadas todas estas novas tendências e vicissitudes, a China ainda está dominando a capa desta revista em termos de reportagem. A cobertura sobre acordos entre China e Japão trata de uma ampla gama de assuntos: comércio agrícola, investimento, aparelhos eletrônicos, finanças e tarifas, produtos de carne, segurança alimentar, produtos de pesca, mudança climática e proteção ambiental, energia, automóveis e outros assuntos. Em termos de número de artigos, o Japão contou com 57 e a China, 253.

\section{WEEKLY ELEVEN NEWS}

Sendo o maior grupo privado de mídia da Birmânia, o Eleven Media Group oferece aos birmaneses um jornal semanal bastante franco, veemente e pró-liberal. Antes da supressão da liberdade de imprensa, o Eleven Media Group tinha assinado um plano de cooperação estratégica com o Thai National Multimedia Group, em um esforço para produzir o primeiro jornal birmanês deste tipo, além de uma estação de televisão.

Dentre 15 assuntos, selecionados entre abril e julho de 2012, as histórias cobriam 18 tópicos, consistindo de 86 artigos e oito notícias sobre Aung San Suu Kyi. Os tópicos referem-se aos 
seguintes aspectos: eletricidade, rede de energia, Congresso, leis de investimento, Estado de Direito, sanções, comércio e investimentos, mídia, protestos, petróleo e gás, reforma, intercâmbio cultural, finanças, comunicação, etnia, segurança alimentar e outros. Em termos de relevância, o foco estava nos países como Estados Unidos, China, Tailândia, Japão, Índia, Reino Unido, União Europeia, e nas Nações Unidas.

O Eleven News tem maior foco em investimento, leis de investimento e no estabelecimento de uma agenda de desenvolvimento econômico. O jornal adota uma postura bastante nacionalista acerca da entrada de investimentos estrangeiros, especialmente provenientes da China e da Tailândia. O Eleven News dedica numerosas páginas ao projeto Dawei, que ultrapassa os U\$ 10 bilhões, financiados pela Tailândia e que, uma vez completado, poderia fazer desse país o maior investidor estrangeiro na Birmânia. Com base em pesquisas da Administração de Informação Energética (EIA, na sigla em inglês) com foco em impacto ecológico e social, este jornal expressou suas suspeitas acerca do projeto em questão, e preocupação com a população birmanesa. O Eleven News tem feito uma campanha crítica e veemente contra a questão das barragens, especialmente sobre o projeto Myistone, tendo publicado três reportagens densas no período de quatro meses, uma reportagem exclusiva sobre a Asia World Company da Birmânia e sobre a continuação das atividades da companhia China Power Investment (CPI) em Myistone.

\section{THE VOICE}

The Voice é uma das revistas noticiosas mais influentes da Birmânia, além de membro do grupo independente de pesquisas Myanmar Egress. De abril a julho de 2012, o The Voice publicou 17 números, que consistiam de 119 histórias, em 23 categorias, sobre 13 países, com 10 artigos sobre Aung San Suu Kyi.

O conteúdo enfoca finanças, eleição, paz étnica, mineração, investimentos, eletricidade, sanções, comunicação, comércio internacional, reforma, mudança climática, automóveis, questões sociais, saúde, Congresso, protestos, Estado de Direito, doações, 
rede de energia, petróleo e gás, mídia e mudança das lideranças. A atenção geográfica se concentra na China, Estados Unidos, Japão, Tailândia, Coréia do Norte, Cingapura, Bangladesh, França, Nações Unidas, a ASEAN e União Européia.

As prioridades do The Voice se dirigem a reconciliação étnica, reforma e protestos sociais. A palavra "reforma" apareceu numerosas vezes nas reportagens desta revista, e os protestos sociais acompanhados por ela são principalmente relacionados a salário e escândalos de aquisição de terras. Em termos de notícias econômicas, o The Voice focaliza telefonia móvel, automóveis e câmbio. Há cinco anos, custaria ao cidadão birmanês cerca de \$3 milhões de kyats para adquirir um número de telefone privado; agora, o preço caiu para \$ 200 mil e até menos, o que logo se refletirá na emergência de uma esfera pública com mídias móveis.

Três países são os mais mencionados: as reportagens sobre os Estados Unidos abordam principalmente a dimensão política, tal como a retirada de sanções econômicas, o endosso à reforma birmanesa, o Estado de Direito e a reconciliação étnica; no que diz respeito à China, as notícias têm maior foco em histórias que tratam de investimentos econômicos, redes hidrelétricas e transações comerciais; já em relação ao Japão, o The Voice elogia a ajuda japonesa à sociedade birmanesa, que deveria ser considerada um investimento stricto sensu, mas conduzida de uma forma social amigável como ajuda.

\section{7DAYS NEWS}

Dentre todas as amostras de mídia selecionadas, o 7 days News adota a postura mais amigável em relação à China e, uma vez, dedicou uma rara história de primeira página ao embaixador da China na Birmânia. Foram publicados 28 artigos relacionados ao Japão e 88, à China; a preferência da mídia se concentra na China, Estados Unidos, Japão, Tailândia, Coréia, Alemanha, Qatar, União Européia e Nações Unidas. 
Fig.2, Descrição básica de conteúdo

\begin{tabular}{|c|c|c|}
\hline Tópico & $\begin{array}{l}\text { Núme- } \\
\text { ro }\end{array}$ & Conteúdo Básico \\
\hline $\begin{array}{l}\text { Funcioná- } \\
\text { rios }\end{array}$ & 1 & $\begin{array}{l}\text { O chefe do Departamento Nacional de Defesa, } \\
\text { promovido a vice-general }\end{array}$ \\
\hline Eleição & 2 & Campanha para eleição de Aung San Suu Kyi's \\
\hline Protesto & 3 & Falta de energia e questões salariais \\
\hline Congresso & 4 & Procedimentos do Congresso \\
\hline Finanças & 3 & Mudança de política monetária \\
\hline Etnia & 12 & Guerra Kachin e questões islâmicas \\
\hline $\begin{array}{l}\text { Partido po- } \\
\text { lítico }\end{array}$ & 5 & $\begin{array}{l}\text { Notícias rotineiras sobre diferentes partidos (ex- } \\
\text { ceto pelo NLD) }\end{array}$ \\
\hline Reforma & 10 & Reforma nacional \\
\hline Sanções & 2 & $\begin{array}{l}\text { Liberação das sanções impostas pelos Estados } \\
\text { Unidos }\end{array}$ \\
\hline Automóveis & 2 & Importação de carros \\
\hline $\begin{array}{l}\text { Investimen- } \\
\text { tos }\end{array}$ & 8 & Investimentos Estrangeiros Diretos (IED) \\
\hline $\begin{array}{l}\text { Segurança } \\
\text { alimentar }\end{array}$ & 3 & $\begin{array}{l}\text { Questões sobre o descarte de óleo e petiscos } \\
\text { chineses }\end{array}$ \\
\hline $\begin{array}{l}\text { Comércio } \\
\text { internacio- } \\
\text { nal }\end{array}$ & 5 & $\begin{array}{l}\text { Visita de Aung San Suu Kyi, o embaixador da } \\
\text { China e entrevista com o embaixador dos Esta- } \\
\text { dos Unidos }\end{array}$ \\
\hline $\begin{array}{l}\text { Petróleo e } \\
\text { gás }\end{array}$ & 2 & $\begin{array}{l}\text { Questões de compensação de cotas do oleoduto } \\
\text { Birmânia-China, investimento tailandês na inte- } \\
\text { gração das redes de gás natural }\end{array}$ \\
\hline Outros & 6 & Educação, saúde e esportes \\
\hline
\end{tabular}

Diferentemente de outros meios que são, pelo menos, indiferentes em relação a políticos chineses, o 7days News ofereceu ao embaixador chinês chances de esclarecer as "sombras" chinesas sobre a sociedade birmanesa. De acordo com o embaixador chinês, é verdade que muito da ajuda chinesa na Birmânia é conduzida por governos dos dois lados, mas o mesmo ocorre entre muitos outros membros da ASEAN. Tal é apenas a rotina internacional que a China tem seguido por um longo tempo, o que, às vezes, ira 
criar problemas e desentendimentos, porém não significa necessariamente que todo o povo birmanês teve negada a chance de se beneficiar destes projetos. Esta entrevista e o sumário da história podem ser vistos como evidência de que o estilo amigável das relações entre China e a Birmânia estava enfraquecendo. Para a maioria da população birmanesa, os investimentos chineses tendem a estarem envolvidos em corrupção, lucros para grupos amigos, nepotismo, desvios e escândalos. Embora a construção de algumas linhas de energia hidrelétrica venha a duplicar ou triplicar a produção de eletricidade birmanesa, para grande parte da opinião pública, a China foi a maior beneficiária de todos estes projetos, os quais são problemáticos no envolvimento das suas comunidades e no design da diminuição do impacto ambiental.

\section{ESTUDO DE CASO E DISCUSSÕES}

\section{PROTESTOS NO OLEODUTO BURMA-CHINA: GRITOS E MURMÚRIOS DA POLÍTICA INTERNA}

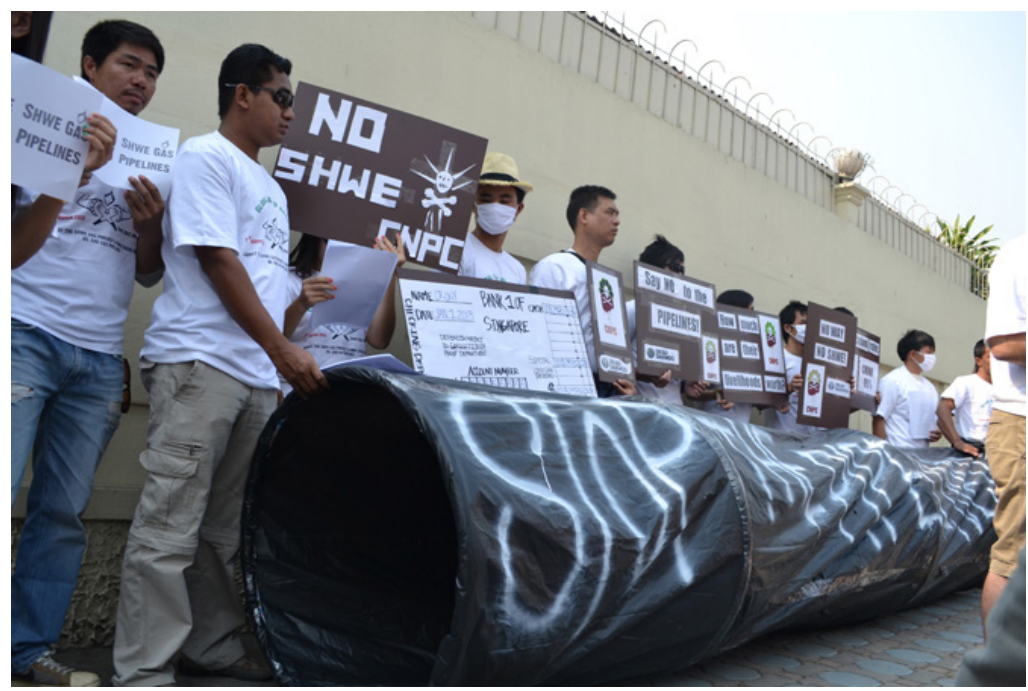

Foto cortesia do Thai news website, acessado em 2012. 
Evidenciado pelo No Shwe Protest, massacre do Rio Mekong e numerosos confrontos paramilitares regionais, a China está tomada pela guerrilha, máfia, protesto social transnacional e política interna em quase todos os seus locais de investimento, espalhados em redor do mundo.

Em $1^{\circ}$. de março de 2012, uma reportagem circulou amplamente entre os leitores chineses. Dizia respeito ao investimento da China em um oleoduto transnacional que estava sendo reclamado e sofria protestos de membros das sociedades locais e organizações internacionais. Esta notícia criou um interessante efeito borboleta retardado, quase 13 meses depois, quando cidadãos de Kunming - a capital da província de Yunnan, no sudoeste da China - tomaram as ruas para protestar contra a instalação de uma fábrica de paraxileno e uma refinaria de óleo em Kunming, especialmente sob o governo ditatorial da China, com zero participação do público. De abril a maio de 2013, cidadãos de Kunming lograram montar dois pequenos protestos e diversos protestos maiores em vão, dada a intervenção estilo GESTAPO exercida pelos chineses - ligações telefônicas de cidadãos sendo interceptadas, intimidações, discussões na mídia sendo silenciadas e censuradas.

Muitos cidadãos chineses tinham conhecimento destes oleodutos apenas como "notícia", quando este projeto era fermentado, cozinhado e arrastado durante anos, senão décadas. Diferentemente, o público e a comunidade birmaneses estavam bem informados e organizados em termos de suas expressões, integração social, negociações e protestos.

Antes que o protesto Shwe se tornasse "notícia", eu já havia recebido de amigos o panfleto digital do "Movimento do Gás Shwe", e o panfleto estava assinalado com uma marca que dizia "Embargado em $1^{\circ}$. de março". Também neste folheto, havia uma longa lista de figuras participantes, tribos, comunidades e organizações, tais como Palaung, Kayan, Kuki, Tavoyan, Ta'ang, Zomi, etc.

Isto tudo mostrava uma população bem organizada, uma esfera pública emergente, uma esfera de campanha internacional engajada, e uma mídia franca e defensora no lado birmanês e nas regiões vizinhas à Birmânia; ao mesmo tempo, um governo chinês 
altamente organizado e militarizado, comunidades pobres e fragmentadas, um sistema de envolvimento social excludente e um regime hiper-conectado, no estilo orwelliano.

Nesta circunstância, o termo "política interna" representa a existência de um grupo oprimido, um mecanismo econômico corrompido, uma distopia digital interconectada e uma paisagem sócio-político-cultural transformadora nestas regiões de fronteira.

O que vejo, como um pesquisador, não é uma situação comum do tipo cara grandão ameaçando o menor e uma história seguida por alvoroço e derramamento de sangue; mas uma transformação mais estrutural e holística nesta região, marcada pelos grupos pobres, grupos étnicos deslocados, herança colonial, globalização pós-socialista, degradação ambiental e perda cultural e, o mais importante de tudo, um ethos étnico que está passando por uma mudança dramática.

Nestas regiões, para os desprivilegiados, refugiados, miseráveis, as reações diante da ameaça externa estão vagarosamente se encaminhando em direção a um processo contraditório de auto-alienação, comunicação transfronteiriça e expansão cultural, os quais eu resumo como Eco-Sionismo ou Movimento de Eco-Restauração - deixando de lado as conotações judias. Para todas estas pessoas, como grupo ou movimento individual, não importa como você os agrupará ou categorizará, eles tendem a fazer com que suas definições sejam fúteis e problemáticas. Apenas em um aspecto, eles tendem a concordar ao invés de divergir: é no que diz respeito à recuperação da terra e na conquista dos interesses comuns, sejam eles concretos ou abstratos, baseados no que eles acreditam que possuem ou deveriam possuir.

Esta é uma era em que a natureza mobiliza e a etnia ecoa.

\section{Tradução: Camila Alves da Costa e Mônica Dias Martins}




\section{REFERÊNCIAS}

APPADURAI, A. Global Ethnoscape, Notes and Queries for a Transnational Anthropology. In: RICHARD G. F. (ed.). Recapturing Anthropology: Working in the Present. Santa Fe, New Mexico: School of American Research Press, 1991. p. 191-238.

ANDERSON, B. Imagined Communities: Reflections on the origin and spread of nationalism, London: Verso, 1983.

BLUM, S. D. Margins and Centers: A Decade of Publishing on China's Ethnic Minorities. The Journal of Asian Studies, v. 61, n. 4, p. 1287-1310, Nov. 2002.

CHARTIER, Roger. Cultural History: Between Practices and Representations. Tranlated by L.G. Cochrane. Cambridge, Oxford: Polity Press with basil Blackwell, 1988.

CLIFFORD, James. 1986. Writing Culture: the Poetics and Politics of Ethnography, ed. J. Clifford and G. Marcus, Berkeley, London: UcalP.

KEYES, Charles F. 'The Peoples of Asia': Science and Politics in Ethnic Classification in Thailand, China and Vietnam," Journal of Asian Studies, 61.4: 1163-1203, Nov. 2002.

FURNIVALL, John. The fashioning of Leviathan. Edited by Gehan Wijeyewardene. An Occasional Paper of the Department of Anthropology, Research School for Pacific Studies, 1991.

LEACH, Edmund. Political Systems of Highland Burma. London: The London School of Economics and Political Science, 1964.

LEFEBVRE, Henri. The Production of Space. Translated by Donald Nicholson-Smith. Oxford: Blackwell Publishers Ltd., 1991.

MICHAELSEN, Scott; JOHNSON, David E. (Eds.). Border Theory: The Limits of Cultural Politics. Mineapolis, London: University of Minnesota Press, 1997.

NORIYUKI, Suzuki; SOMSAK, Srisontisuk. (Ed.). Civil Society Movement and Development in Northeast Thailand. Khon Kaen University Book Center, 2008.

ONG, Aihwa. Flexible Citizenship: The Cultural Logics of 
Transnationality. Durham \& London: Duke University Press, 1999.

Neoliberalism as Exception: Mutations in Citizenship and Sovereignty. Durham and London: Duke University Press, 2006.

OSBORNE, Milton. The Mekong: Turbulent Past, Uncertain Future. New York: Grove Press, 2000.

WALKER, A. (ed.). Tai Lands and Thailand: Community and State in Southeast Asia. Asian Studies Association of Australia in association with NUS, Singapore and NIAS, Copenhagen, 2009.

ZHOU Lei. Anthropolis: Reflections upon Chinese Ecological Problems (in Chinese), Beijing Institute of Technology Publishing House, 2012. 